\title{
Potensi Biji Kolowe (Chydenanthus excelsus) Sebagai Pisisidal
}

\author{
Laode Rijai \\ Laboratorium Kimia Farmasi Fakultas Farmasi Universitas Mulawarman, Kampus UNMUL Gn. Kelua, \\ Samarinda, Kalimantan Timur \\ email : najwankhanrjai@yahoo.co.id
}

\begin{abstract}
Kolowe seeds (C. excelsus) has strong potential as piscicidal. Research conducted on the potential piscicidal bioindikator swamp eel fish (Synbranchus bengalensis Mc.Cllel), which is one of the pests in shrimp ponds. The piscicidal test results of kolowe seeds to S.bengalensis fish are fresh seed powder $(L C 50=305,50 \mathrm{ppm})$; dry powder $(L C 50=315.35 \mathrm{ppm})$; crude methanol extract $(L C 50=345.20$ ppm $)$; frakasi $n$-Butanol extract $(L C 50=265.85)$ and the fraction of ethylacetate extract $(L C 50=650.90)$. The results are quite robust and selective as the most dominant secondary metabolites are saponins.
\end{abstract}

Key words: C. excelsus, Piscicidal

\begin{abstract}
ABSTRAK
Biji kolowe (C. excelsus) memiliki potensi yang kuat sebagai pisisidal. Penelitian potensi pisisidal dilakukan terhadap bioindikator ikan belut rawa (Synbranchus bengalensis Mc.Cllel) yang merupakan salah satu hama pada tambak udang. Hasil uji pisisidal biji kolowe terhadap ikan S.bengalensis tersebut adalah serbuk biji segar $\left(\mathrm{LC}_{50}=305,50 \mathrm{ppm}\right)$; serbuk kering $\left(\mathrm{LC}_{50}=315,35 \mathrm{ppm}\right)$; ekstrak kasar metanol $\left(\mathrm{LC}_{50}=345,20 \mathrm{ppm}\right)$; ekstrak frakasi n-Butanol $\left(\mathrm{LC}_{50}=265,85\right)$; dan esktrak fraksi etilasetat $\left(\mathrm{LC}_{50}=650,90\right)$. Hasil penelitian tersebut cukup kuat dan selektif karena metabolit sekunder paling dominan adalah saponin.
\end{abstract}

Kata Kunci: Biji C. excelsus, pisisidal

\section{PENDAHULUAN}

Tumbuhan kolowe adalah spesies langka yang hanya ditemukan di kepulauan Andaman, Myanmar dan kepulauan Buton, Indonesia [1]. Tumbuhan ini berbuah secara terus menerus atau tidak bermusim. Buah dan daunnya digunakan oleh masyarakat Kamaru, Buton sebagai racun ikan, bahkan menjadi bahan untuk menangkap ikan laut pada areal laut pasang surut kering (surut hingga kering). Belum ada kasus pencemaran akibat penggunaan buah tersebut pada areal perairan. Secara kimia sifat racun ikan dapat disebabkan oleh metabolit sekunder kelompok saponin, selain kelompok senyawa lainnya.

Saponin memiliki multi potensi seperti racun ikan (fisisidal), sitotoksik, bakterisida, insektisida, antifeedant, fungisida, dan berbagai obat-obatan lainnya) ${ }^{2}$. Dari aspek ilmiah, penelitian saponin berpeluang menemukan senyawa baru karena kelompok senyawa ini sangat bervariasi jenisnya dan sukar dipisahkan dengan teknik-teknik pemisahan konvensional. Selain itu keberadaan saponin dalam suatu spesies dapat menggambarkan biogenesis spesies 
tersebut karena saponin adalah bentukan dari triterpen/steroid dengan molekul gula.

Dengan demikian penelitian saponin dari suatu spesies memberikan manfaat aplikasi dalam pemanfaatan spesies sebagai sumber bioaktif dan manfaat ilmiah dalam aspek temuan baru senyawa dan biogenesis spesies. Biji kolowe mengandung saponin sebagai konstituen utama hingga 46,2 \% pada fraksi $n$-butanol [3].

Penggunaan biji kolowe sebagai racun ikan oleh masyarakat merupakan petunjuk utama pengujian sebagai pisisidal. Potensi tersebut berhasil guna jika memiliki sifat selektif yaitu hanya dapat membunuh ikan yang dianggap sebagai hama misalnya pada tambak. Perlakuan pendahuluan menunjukan bahwa biji kolowe tidak dapat mematikan udang pada tambak meskipun belum dilakukan eksperimen secara ilmiah. Karena itu penelitian berikutnya yang harus dilakukan adalah identifikasi selektivitas sifat pisisidal dari biji kolowe.

Potensi pisisidal sangat bernilai ekonomi dalam petani tambak, karena Indonesia mengimpor biji teh dari China sebagai sumber pisisidal karena biji teh mengandung saponin yang sangat dominan.

\section{METODE}

\section{a. Pengumpulan dan Penyiapan Bahan Sampel Uji}

Bahan tumbuhan diambil dari Kamaru, Buton, Indonesia, karena tumbuhan tersebut di Indonesia baru ditemukan di daerah tersebut. Sebanyak 38 buah kolowe segar dikupas dan diperoleh biji segar 1480 g. Biji kolowe tersebut diarajang lalu dikeringkan dengan cara menjemur pada sinar matahari langsung dengan menghindarkan hujan. Penetapan bahwa biji kolowe telah kering dilakukan dengan pengamatan secara visual fisik bahan dan pengukuran kadar air hingga toleransi $5 \%$.

Biji kolowe yang telah dinyatakan kering, digiling dengan blender hingga diperoleh serbuk kering. Serbuk kering yang diperoleh dari pengerjaan tersebut adalah 950 g. Untuk mendapatkan jumlah serbuk yang lebih banyak, dilakukan ulangan dengan cara yang sama. Selanjutnya, 800 $\mathrm{g}$ serbuk kering tersebut dimaserasi dengan metanol 5x 24 jam @ 2 L.

Ekstrak yang diperoleh setelah pelarutnya diuapkan adalah 245 g. Sebanyak 100 g ekstrak kental tersebut difraksinasi secara gradien yaitu dengan etilasetat:air dan $n$-butanol:air. Ekstrak hasil fraksinasi yang diperoleh masing-masing etilasasetat dan $n$-butanol adalah 12,5 g dan 31,8 g.

Dengan demikian jumlah sampel yang siap untuk perlakuan berikutnya pada pengerjaan pertama adalah: serbuk kering $150 \mathrm{~g}(950 \mathrm{~g}-800 \mathrm{~g}), 145 \mathrm{~g}$ ekstrak metanol $(245 \mathrm{~g}-100 \mathrm{~g}), 12,5 \mathrm{~g}$ ekstrak fraksi etilasetat, dan 31,8 g ekstrak fraksi n-butanol. Untuk mendapatkan ekstrak yang lebih banyak, dilakukan pengerjaan ulangan dengan prosedur tersebut.

\section{b. Penyiapan Ikan Belut Rawa ( $S$. bengalensis Mc.Cllel) Sebagai Bioindikator Uji}

Benih ikan belut Rawa diambil dari kolam pemijahan Jurusan Budidaya, Fakultas Perikanan, Universitas Mulawarman. Umur benih yang digunakan adalah 2-3 bulan yang berwarna keemasan. Benih-benih tersebut dipelihara dalam aquarium selama 1 minggu yang diberi makan keong emas. 


\section{c. Penentuan Seri Kosentrasi Sampel Uji}

Berdasarkan hasil pengujian penentuan kosentrasi batas bawa dan batas atas, maka seri kosentrasi percobaan yang digunakan ditunjukkan pada Tabel 1.

\section{c. Pengujian Pisisidal}

Untuk pengujian, menggunakan aquarium mini yang dilengkapi dengan aerator. Empat aquarium eksperimen telah disiapkan yang telah berisi air suling dan ekstrak sampel sesuai dengan seri kosentrasi yang telah ditentukan.

Setiap aquarium tersebut dimasukan 20 ekor benih ikan belut rawa. Pengamatan dimulai 90 menit setelah perlakuan. Rancangan pengujian ditunjukkan pada Tabel 2 dan Tabel 3.

Rancangan penelitian menggunakan Rancangan Acak Lengkap (RAL) yang terdiri dari dua faktor yaitu faktor perlakuan dan faktor pengamatan.

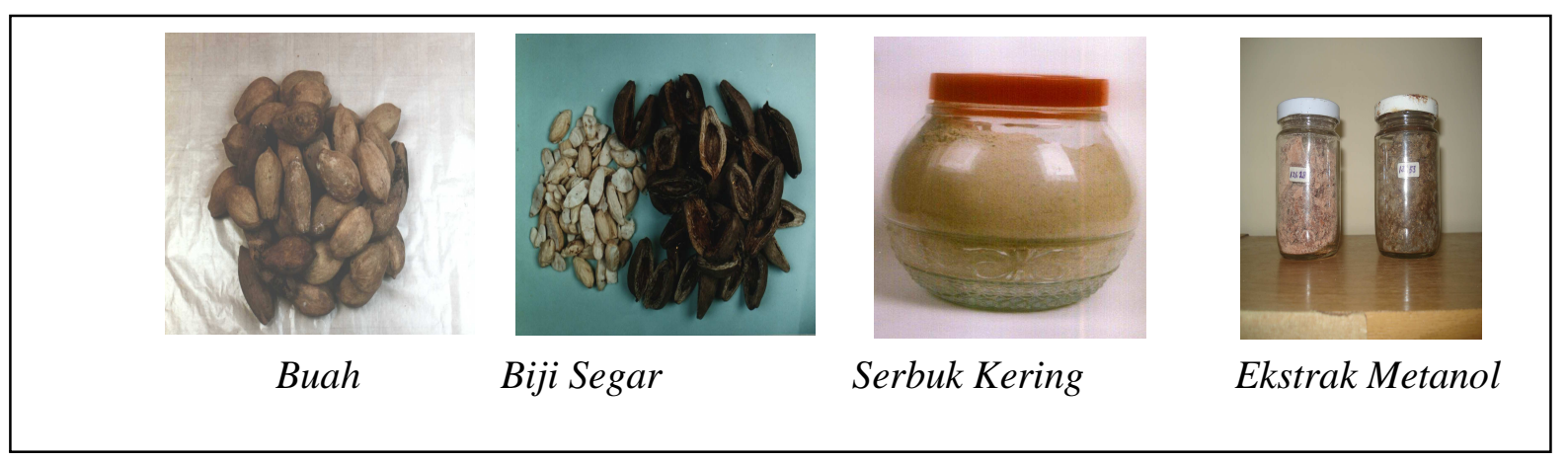

Gambar 1. Buah kolowe dalam berbagai bentuk fisik

Tabel 1. Seri kosentrasi Uji bioaktivitas pisisidal terhadap benih ikan belut rawa (S. bengalensis)

\begin{tabular}{|c|c|c|c|c|c|}
\hline \multirow{2}{*}{ Ulangan } & \multicolumn{5}{|c|}{ Kosentrasi dalam ppm } \\
\hline & 200 & 400 & 600 & 800 & Kontrol \\
\hline \multicolumn{6}{|l|}{ I } \\
\hline \multicolumn{6}{|l|}{ II } \\
\hline \multicolumn{6}{|l|}{ III } \\
\hline & Rata-rata & Rata-rata & Rata-rata & rata & \\
\hline
\end{tabular}

Tabel 2. Rancangan pengujian pisisidal biji Kolowe (C. excelsus) Serbuk Segar, Serbuk Kering dan Ekstrak Kasar Metanol terhadap ikan belut rawa (S. bengalensis)

\begin{tabular}{|c|c|c|c|c|c|c|c|c|}
\hline \multicolumn{3}{|c|}{ Serbuk Segar (SS) } & \multicolumn{3}{|c|}{ Serbuk Kering (SK) } & \multicolumn{3}{|c|}{ Ekstrak Metanol (EM) } \\
\hline $\mathrm{SSK}_{1} \mathrm{U}_{1}$ & $\mathrm{SSK}_{2} \mathrm{U}_{1}$ & $\mathrm{SSK}_{3} \mathrm{U}_{1}$ & $\mathrm{SKK}_{1} \mathrm{U}_{1}$ & $\mathrm{SKK}_{2} \mathrm{U}_{1}$ & $\mathrm{SKK}_{3} \mathrm{U}_{1}$ & $\mathrm{EMK}_{1} \mathrm{U}_{1}$ & $\mathrm{EMK}_{2} \mathrm{U}_{1}$ & $\mathrm{EMK}_{3} \mathrm{U}_{1}$ \\
\hline $\mathrm{SSK}_{1} \mathrm{U}_{2}$ & $\mathrm{SSK}_{2} \mathrm{U}_{2}$ & $\mathrm{SSK}_{3} \mathrm{U}_{2}$ & $\mathrm{SKK}_{1} \mathrm{U}_{2}$ & $\mathrm{SKK}_{2} \mathrm{U}_{2}$ & $\mathrm{SKK}_{3} \mathrm{U}_{2}$ & $\mathrm{EMK}_{1} \mathrm{U}_{2}$ & $\mathrm{EMK}_{2} \mathrm{U}_{2}$ & $\mathrm{EMK}_{3} \mathrm{U}_{2}$ \\
\hline $\mathrm{SSK}_{1} \mathrm{U}_{3}$ & $\mathrm{SSK}_{2} \mathrm{U}_{3}$ & $\mathrm{SSK}_{3} \mathrm{U}_{3}$ & $\mathrm{SKK}_{1} \mathrm{U}_{3}$ & $\mathrm{SKK}_{2} \mathrm{U}_{3}$ & $\mathrm{SKK}_{3} \mathrm{U}_{3}$ & $\mathrm{EMK}_{1} \mathrm{U}_{3}$ & $\mathrm{EMK}_{2} \mathrm{U}_{3}$ & $\mathrm{EMK}_{3} \mathrm{U}_{3}$ \\
\hline
\end{tabular}

Tabel 3. Rancangan pengujian pisisidal biji Kolowe (C. excelsus) Ekstrak fraksi Etilasetat dan Ekstrak fraksi nButonol terhadap ikan belut rawa (S. bengalensis)

\begin{tabular}{llllll}
\hline \multicolumn{3}{c}{ Ekstrak Fraksi Etilasetat (EA) } & \multicolumn{3}{c}{ Ekstrak fraksi $\boldsymbol{n}$-Butanol (B) } \\
\hline $\mathrm{EAK}_{1} \mathrm{U}_{1}$ & $\mathrm{EAK}_{2} \mathrm{U}_{1}$ & $\mathrm{EAK}_{3} \mathrm{U}_{1}$ & $\mathrm{BK}_{1} \mathrm{U}_{1}$ & $\mathrm{BK}_{2} \mathrm{U}_{1}$ & $\mathrm{BK}_{3} \mathrm{U}_{1}$ \\
$\mathrm{EAK}_{1} \mathrm{U}_{2}$ & $\mathrm{EAK}_{2} \mathrm{U}_{2}$ & $\mathrm{EAK}_{3} \mathrm{U}_{2}$ & $\mathrm{BK}_{1} \mathrm{U}_{2}$ & $\mathrm{BK}_{2} \mathrm{U}_{2}$ & $\mathrm{BK}_{3} \mathrm{U}_{2}$ \\
$\mathrm{EAK}_{1} \mathrm{U}_{3}$ & $\mathrm{EAK}_{2} \mathrm{U}_{3}$ & $\mathrm{EAK}_{3} \mathrm{U}_{3}$ & $\mathrm{BK}_{1} \mathrm{U}_{3}$ & $\mathrm{BK}_{2} \mathrm{U}_{3}$ & $\mathrm{BK}_{3} \mathrm{U}_{3}$ \\
\hline
\end{tabular}

Keterangan: $\mathrm{EAK}_{1} U_{1}=$ perlakuan konsentrasi 1 ekstrak frakasi etilasetat pada ulangan 1 dst... 


\section{HASIL PENELITIAN DAN PEMBAHASAN}

Bioindikator untuk uji pisisidal adalah ikan belut rawa (Synbranchus bengalensis Mc.Cllel). Belut merupakan hama pada tambak udang karena ia merupakan pemakan daging dengan jenis makanan udang, ikan mujair, siput, cacing, dan lainlain. Sifatnya yang demikian itu yang menyebabkan sebagai hama tambak udang dan ikan. Belut rawa dapat hidup di air payau sehingga merupakan hama pada tambak udang dan tambak ikan bandeng. Hasil pengujian biji kolowe terhadap bioindikator belut rawa ( $S$. bengalensis) terlihat pada tabel 4 .

Hasil pengujian tersebut menunjukkan bahwa ekstrak $n$-butanol memiliki bioaktivitas yang lebih kuat, demikian pula biji segar dan serbuk kering. Kuatnya bioaktivitas ekstrak $n$-butanol berasal dari saponin yang terkandung pada fraksi tersebut. Saponin adalah kelompok kimia alami yang umumnya sebagai racun ikan dan digunakan untuk pengendalian hama tambak udang dan tambak ikan. Di Indonesia sumber saponin yang biasa digunakan untuk pengendalian hama tambak ikan/udanga adalah biji teh. Karena itu, biji kolowe yang telah diketahui mengandung saponin tinggi diharapkan dapat menjadi sumber saponin untuk pengendalian hama tambak udang/ikan.

Hasil uji bioaktivitas biji kolowe (Tabel 4) menggambarkan bahwa sediaan segar dan serbuk kering memiliki bioaktivitas yang relatif sama. Hal ini menunjukkan bahwa jika biji kolowe dapat digunakan secara luas khususnya untuk pengendalian hama belut dapat dikemas dalam bentuk serbuk kering sehingga mudah untuk pengiriman. Namun demikian masih diperlukan penelitian lanjutan tentang stabilitas bioaktivitas serbuk untuk penyimpanan. Selain itu, penelitian penting biji kolowe yang perlu dilakukan terkait dengan penggunaannya sebagai fisisidal adalah uji lapang terhadap ikan belut.

Tabel 4. Hasil uji bioaktivitas fisisidal biji kolowe (C. excelsus) terhadap benih ikan belut rawa (S. bengalensis)

\begin{tabular}{clc}
\hline No & \multicolumn{1}{c}{ Bahan } & Nilai Lethal Concentration (LC50) dalam ppm \\
\hline 1 & Serbuk Biji segar & 305,50 \\
2 & Serbuk kering & 315,35 \\
3 & Ekstrak kasar (metanol) & 345,20 \\
4 & Ekstrak fraksi $n$-butanol & 265,85 \\
5 & Ekstrak fraksi etilasetat & 650,90 \\
\hline
\end{tabular}

\section{KESIMPULAN DAN SARAN}

Berdasarkan hasil penelitian tersebut, maka dapat disimpulkan bahwa biji kolowe berpotensi digunakan sebagai pisisidal terutama pada tambak udang, sedangkan untuk tambak ikan masih perlu dilakukan pengujian selektivitas aktivitas pisisidal.

Penelitian selektivitas aktivitas pisisidal terhadap ikan petani tambak untuk memastikan penggunannya terhadap berbagai tambak termasuk tambak ikan.

\section{DAFTAR PUSTAKA}

1. Harriman, N. 1997, Plants Number Index. Biology Department, Univeristy of Wisconsin, Oskhosh.

2. Hostettman, K.; \& A. Marston. 1995, Saponins: A Chemistry and Pharmacology of Natural Products. Cambridge University Press, First Published. New York.

3. Rijai, L. 2004, Kajian Kimiawi dan Biokativitas Tumbuhan Kolowe (Chydenanthus excelsus). Disertasi, UNPAD, Bandung

4. Colegate, S. M.; \& R. J. Molyneux. 1993, In Bioactive Natural Products: Detection, 
Potensi Biji Kolowe (C. excelcus) Sebagai Pisisidal

isolation, and structural determination, (3rd edition), 349-399, CRC Press, Boca Raton, London, Tokyo.
5. Rijai, L. 2007, Kajian Bioaktif Potensial Biji Kolowe (Chydenanthus excelsus) untuk Pemanfaatan, LPPM, UNMUL, Samarinda 